\title{
Art Evolution of the Ancient Jade Vortex Pattern
}

\author{
Yuan Xie, Kai Ren, Wenjing Min \\ College of Jewelry, China University of Geosciences, Wuhan, China \\ Email:173538239@qq.com
}

How to cite this paper: Xie, Y., Ren, K., \& Min, W. J. (2021). Art Evolution of the Ancient Jade Vortex Pattern. Art and Design Review, 9, 309-315.

https://doi.org/10.4236/adr.2021.94026

Received: September 16, 2021

Accepted: October 18, 2021

Published: October 21, 2021

Copyright $\odot 2021$ by author(s) and Scientific Research Publishing Inc. This work is licensed under the Creative Commons Attribution International License (CC BY 4.0).

http://creativecommons.org/licenses/by/4.0/

\begin{abstract}
As the ontology structure of vortex pattern, no matter the development of society, aesthetic concept and technology, it can always find the most ontology structure in decoration, shape and technology. From the perspective of jade, the paper analyzes the evolution and reconstruction of the material characteristics and technological characteristics of the jade itself, and explores the cultural and artistic value hidden behind the decoration.
\end{abstract}

\section{Keywords}

Vortex Pattern, Jade, Aesthetic Consciousness, Cultural Consciousness, Ornament, Modelling

\section{Introduction}

The vortex pattern was produced in the early Neolithic period, which is the earliest curve pattern in the primitive period. After the complicated evolution, reorganization, integration and innovation of various eras, the vortex pattern has imperceptibly infiltrated into all kinds of various art forms. At present, many scholars have had some studies on vortex lines. For example, such as Mr. Hainino's Decoration and Human Culture (Hainino, 1990), they analyzed the morphological characteristics and approximate decorative structure characteristics of the rope knot, thunder, rolling grass and other patterns one by one, and explored the relationship with the original spiral lines in the origin; according to the "birth of modeling" (Sugiura, 2013) by Sugiura Kohei, Japanese, it also expounds the view of vortex grain as the subject of pattern evolution according to the characteristics and structural forms of vortex decoration in different eras and regions. However, most scholars have expounded the research of vortex lines based on the modeling and symbolic level presented by the graphic art form as 
the carrier. The author thinks that jade is the memory hard disk of Chinese civilization and the carrier to record the development of religion, art and culture. From the perspective of ancient jade, the vortex grain is modern image interpretation, combined with the characteristics of its technology development, to obtain the human cultural thoughts and aesthetic concepts presented in the jade carving art.

\section{The Origins of Vortex Patterns}

\subsection{The Origin of Aesthetics Consciousness of Vortex Patterns}

Human aesthetic consciousness originated in the interaction process of human beings and nature, and is the perception and reflection of human beings after receiving the stimulation of natural things. The original aesthetic consciousness originated from production and labor, so it returned to ancient cultural heritage. The earliest vortex pattern was found on pottery tablets unearthed from the site in Mengxi Town, Lixian County, Hunan Province (Figure 1). The accumulation mainly belongs to the Neolithic culture, about 8500 - 7500 years ago. This period belongs to the period of change of olithic and Neolithic, stone mill, pottery appeared. Due to the characteristics of ceramic products materials, the ancients can use surface treatment by pressing, stamping, pressing, stamping and printing before high temperature firing. Early geometric patterns were mainly repeated application of points, straight lines and folding lines, and the artistic composition form tended to mature, while the vortex patterns were not systematic at first due to the difficulty in control of the arc. For example, the vortex pottery tablets of 6400-Daxi Cultural Chengtou Mountain Site 5300 ago (Figure 2) and the whirlpool pottery tablets of 5300 - 4600 ago (Figure 3) are presented in the form of single elements. Until the vortex color pottery unearthed from Majiayao culture (about 5000 - 4050 ago) (Figure 4) appeared, the vortex pattern was staggered, round and smooth, with a strong sense of rhythm and rhythm, and it is difficult to hide its aesthetic thoughts. It can be seen that from the Neolithic period, in the processing of art, has initially reflected the characteristics of diverse unity, balance and symmetry, and can make various changes with different shapes and coordination. This reflect the pattern in our country in the bud, has paid

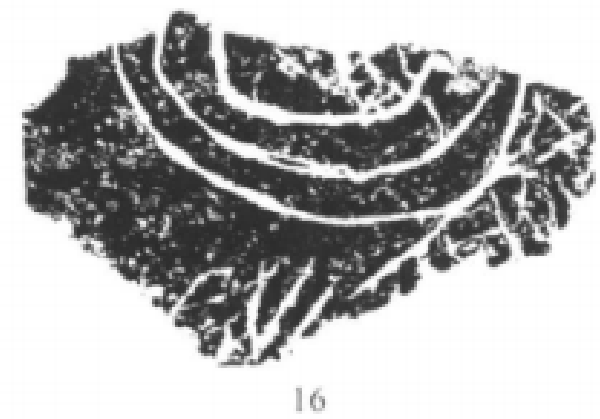

Figure 1. Swirling pottery tablets at the 80 weir site (Hunan Provincial Institute of Cultural Relics and Archaeology, 2006). 

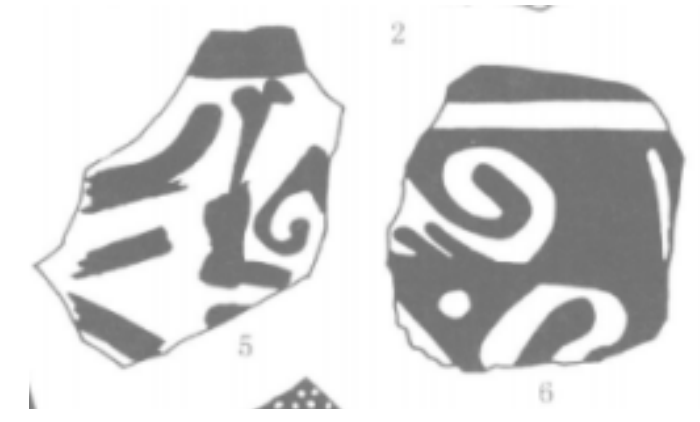

Figure 2. Swirling pottery tablets at Daxi Cultural Chengtou Mountain Site (Hunan Provincial Institute of Cultural Relics and Archaeology, 2007).
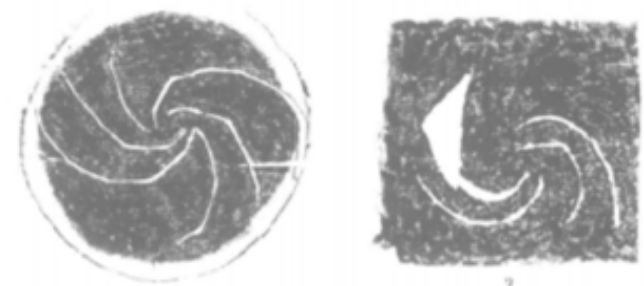

Figure 3. Swirling pottery tablets at Qujialing Cultural Site (Hunan Provincial Institute of Cultural Relics and Archaeology, 2007).

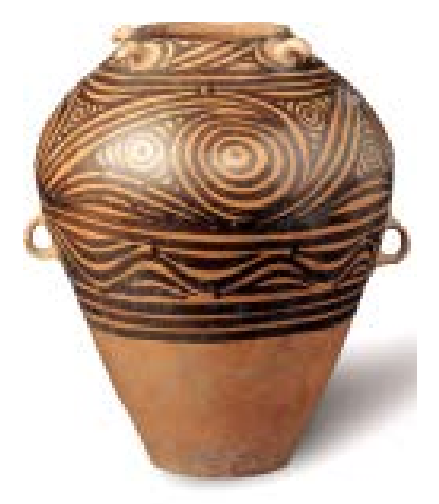

Figure 4. Majiayao culture vortex grain colored pottery (Yang, 2016).

attention to practical and beautiful combination, shape and decoration unified. At the same time, it also shows the rich creativity and imagination of our ancestors.

Moreover, due to the awakening of cultural function and aesthetic consciousness, the shape of curves continues to emerge, from a single style to dynamic, rhythm, or the complete curve of conscious depiction with ease, or unconscious artistic behavior extraction obtain new forms. From the perspective of shape system alone, the vortex pattern in other patterns, as the subject of development, began to evolve new curved variants of specific aesthetic consciousness, social habits and worship beliefs, which is the original formal beauty summary of the vortex pattern (Figure 5). Therefore, if a single dot, straight line, and broken line decoration form represents the beginning of conscious modeling art imitation, then the art pattern and modeling mode displayed by the curve vortex pattern 


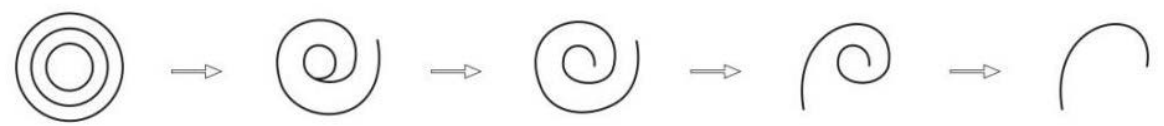

Figure 5. Simulation of the conscious imagery process of the primitive period vortex lines (drawn by the author).

can be said to be the beginning of conscious modeling art aesthetic.

\subsection{The Origin of the Cultural Consciousness of the Vortex Patterns}

The cultural consciousness of artistic subjects is not inherent in the human brain, but is attached to the social environment. It is closely related to the external environment of human survival and the sensory experience given by this environment. It is a kind of perception of things, and the sum of ideas, ideas, concepts, values and other elements. The earliest vortex lines in the Neolithic Age are, on the one hand, are the inspiration of relevant objects in nature, such as the halo of the sun, the ripples of raindrops, the whirlwind rolled up, the attitude of Fujimans winding, the winding of insects and snakes, and the natural texture of the nut shell, etc. On the other hand, it stems from the influence of original production practices, such as tying rope, mixing clay, the peripheral movement of the body wrist, the traces of fingerprint pressing on the clay, and the imperceptible influence of the morphology seen in these natural environment and living conditions, the cognitive consciousness of the ancient people. This imitation is human nature and instinct, and is the main method of original artistic creation. However, some scholars believe that the vortex lines created by the Neolithic ancestors because of imitation are only based on the imitation of object shape, and did not achieve the imitation of substantive concept. Therefore, another view of the origin of the vortex pattern in the Neolithic period is worship and totem theory. For example, the vortex pattern looks endless growth, week after week, the sun and the moon, and the cold and heat symbolize the modeling characteristics of the natural movement of the universe, the sun, the moon and other objects. The ancients depict vortex curve intention under the guise of natural power to establish a connection to master life, the universe and other mysterious world, and out of a awe of god or give natural life interpretation of cognitive state, may make the vortex condensation at the beginning of multiple subjective consciousness and mysterious function, this case of vortex pattern is not simple imitation, is a kind of conscious artistic behavior activities. Therefore, the original formation and function of the vortex pattern may have a great thing to do with nature worship and sacrificial prayer.

\section{Application and Artistic Value of Vortex Grain in Jade}

According to the existing archaeological data, more than 20 representative cultures were covered during the Neolithic period of $\mathrm{BC}$, and they experienced nearly 24 historical dynasties after the establishment of the national system. In the historical changes of nearly 10,000 years, jade carries the spiritual belief of the Chi- 
nese nation and is known as the "spirit of mountains and rivers", which can understand heaven and earth, eliminate evil, and know the disasters and blessings. Based on various factors of materials, culture, religion, technology and aesthetic appreciation, the form of jade is from simple and mysterious, Jade Jue, Jade Cong, Jade Huang to exquisite Jade Pei, Jade Pot and Jade Tripod, and the evolution of the pattern is from unconscious extraction to conscious precipitation, thus forming a complete jade culture system of the Chinese nation.

\subsection{The Plastic Art Value of the Vortex Patterns}

In his book Chinese Original Art Spirit, Mr. Zhang pointed out: "formal structure, as a carrier of primitive concept and meaning, continues to develop towards self-sufficiency in evolution. Due to the maturity of the subject aesthetic psychology and the diversification of behavior, as well as the increasingly pure mastery of technology, the diversity of forms is produced" (Zhang, 2004). (Dong, 2007) from the perspective of the aesthetic consciousness and cultural consciousness background of the vortex lines, the curve form produced in the vortex modeling consciousness is the root of the universe, the dualistic world view of movement and quiet, life and death, Yin and Yang. It is a movement form of infinite circulation and an infinite continuous life. This vortex contains everything in the universe. Japanese design master Sugiura, K. has proposed in the birth of the modelling of the book vortex pattern as the main body exists in the vortex (symbol of lightning, thunder, clouds and plant pattern shape with strong vitality), vortex (a symbol of primitive society beast dragon, phoenix, snake and represents the strong life power of turtle, fish decoration), human vortex (internal natural form such as finger vortex, eye vortex, etc.) three pattern system in details. The author also thinks that for curve lines, vortex lines are the origin of curve lines. From the perspective of the law of art development, once the increasing aesthetic experience, functional needs and performance requirements come to a certain extent, they will break through the original form framework to seek an expression form suitable for themselves. In addition, contemporary scholars including Dong, J., $\mathrm{Xu}, \mathrm{J} . J$. and Dong, L. have also published the view that the vortex pattern as the original form language shapes the new vortex structure with the development of the times.

From the perspective of the law of art development, the vortex pattern as the origin of the curve pattern, when the increasing aesthetic experience, functional needs, performance requirements to a certain extent, will break through the original formal framework to seek a suitable expression form, so as to promote a new structural form. From the perspective of jade surface grain, similar to nature, heaven, grain, thunder grain, hook, grain, latex, silk grain in the production and use of the jade surface, although the ancients have given it a specific meaning, from the Neolithic period has appeared jade, for example, early jade is given priority to sacrifice blessing, with grain used to place the hope of survival. Clouds, thunder are the awe of natural images; Pu grain worship heaven, earth, moun- 
tains and rivers to live and work in peace and contentment. But this kind of vortex pattern in form from the main structure, stylized main element-vortex pattern, still belong to the vortex pattern decorative form using the curve repetition, contrast, balance, scattered artistic means of the artistic reconstruction, constantly consciously extract all kinds of vortex pattern (Figure 6). From the perspective of view of shape, the mythical dragon-shaped, phoenix and bird-shaped Pei basically show the shape of the "C"-shaped, "S"-shaped, double "S"-shaped, " $\Omega$ "-shaped, “ $M$ "-shaped and so on. Line and shape height as a whole, line, in the abstract flow of decorative lines show the unique time characteristics and the original mysterious form, its results not only present the dragon, phoenix, bird, such as animal own divine power, symbol, worship, blessing, etiquette, at the same time shows the ancient modelling art development law, the interpretation of the ancient curve deconstruction art method.

\subsection{Process Application Value of Vortex Pattern}

Jade carving technology is one of the important carriers of Chinese traditional culture. Jade carving works from different eras represent the highest level of handicraft development in that period. According to the cutting technology elaborated by the archaeologist Mr. Mou, Mr. Yang and other archaeologists of the prehistoric jade carving technology of the unearthed jade characteristics institute, the jade carving techniques mastered by the ancient people ranged from the early Yin line carving, bas-relief, carving, round carving to the late double hook Yin carving line, one slope and Han Dynasty. Whirl pattern as curved line evolution symbol whether used as decorative pattern (jade known as grain) or shape modeling, relying on updated technology, technology and materials, collision, the form of two-dimensional plane carving to 2.5 dimensional relief, finally threedimensional hollow carving, such as through modern technology of jade surface archaeological analysis, Neolithic curve engraving effect is directly using hard carving, apply countless short straight line dry scratch group. From the Yin and Shang period, fine weight-shaped jade tools have been produced, and the shape characteristics of the curve are empty and inter structure has made a qualitative leap. But no matter which process is presented, the curve is one of the important starting points for contemporary archaeologists to obtain information. It can not only find the processing rules of jade, but also understand the technological inheritance and innovation in different periods and the

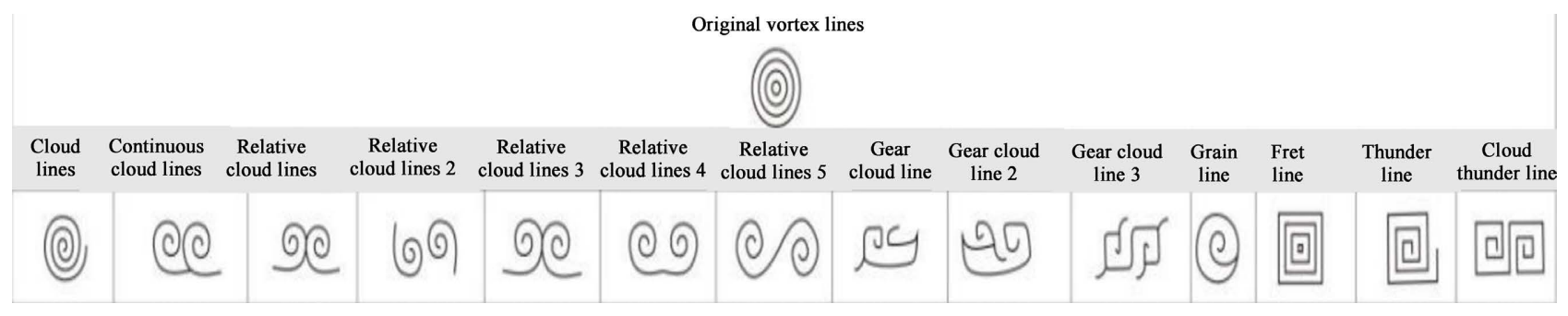

Figure 6. The induction of deconstruction art form. 
communication and penetration between cultural and aesthetics in different regions.

\section{Conclusion}

The application form of vortex pattern is one of the most widely used and active traditional decoration in the traditional Chinese jade carving art and even modern design fields such as plane, architecture, jewelry and textile. In addition, following the main aesthetic consciousness, cultural consciousness and technology over a long period of time, mutual integration, the vortex lines will continue to evolve, restructuring, integration, innovation, evolve into a variety of vortex lines with the characteristics of the times to form a new style. This process imperceptibly permeates all corners of human civilization, reflects the complex relationship between human cultural thought, industrial technology development and aesthetic concept evolution, represents the crystallization of the wisdom, culture and aesthetic appreciation of countless ancestors of the Chinese nation, and also reflects the endless creativity and imagination of our ancestors. Therefore, as contemporary art workers, we should maintain the development and inheritance of traditional Chinese decoration. We should draw the essence from the treasure house of traditional culture and art. While emphasizing the sense of the times of design development, we need to make modern design rooted on the fertile soil of the nation and tradition, and provide more meaningful and more meaningful ideological and cultural support for modern art.

\section{Conflicts of Interest}

The authors declare no conflicts of interest regarding the publication of this paper.

\section{References}

Dong, J. (2007). Research on the Characteristics and Application of Chinese Cloud. Ph.D. Thesis, Xi'an University of Engineering, 15-16.

Hiroshi, U. (1990). Decoration and Human Culture (pp. 21-22). Shangdong Fine Arts Press.

Hunan Provincial Institute of Cultural Relics and Archaeology (2006). Pengtou Mountain and Eighty Gear (pp. 331). Science Press.

Hunan Provincial Institute of Cultural Relics and Archaeology (2007). Excavation Report of: Neolithic Site in Chengtou Mountain, Lixian County (pp. 362-518). Cultural Relics Press.

Sugiura, K. (2013). The Birth of Style: Image Cosmology (pp. 56-57). China Renmin University Press.

Yang, F.H. (2016). The Application of the Original "Modernism"-Horse Home Kiln Colored Pottery Vortex Pattern in Modern Art Design. Northwest Art, 1, 92.

Zhang, X.L. (2004). Chinese Original Art Spirit (Vol. 4, pp. 46-47). Chongqing Publishing House. 